\title{
NOTES ON THE OCCURRENCE OF LARGE QUANTITIES OF HÆMATOPORPHYRIN IN THE URINE OF PATIENTS TAKING SULPHONAL. ${ }^{1}$
}

\author{
By Archibald E. Garrod, M.A., M.D., F.R.C.P., and \\ F. Gowland Hopkins, M.B., B.Sc., F.I.C.
}

MANY cases have recently been recorded in which urine of a deep red colour has been passed, which has proved on examination to be free from unaltered blood pigment, but to contain large quantities of an iron-free derivative of hæmnglobin, namely, hæmatoporphyrin. We are not here confronted with the occurrence in the urine of an unusual or exceptional ingredient, for traces of hæmatoporphyrin are usually, if not constantly, present in normal human urine, and under a great variety of morbid conditions larger amounts are met with in specimens which nevertheless exhibit no marked peculiarity of tint. On the other hand, the quantity of the pigment present in these dark red urines is far in excess of that met with in ordinary morbid specimens.

The evidence which connects the phenomenon under consideration with the administration of sulphonal is so cogent that the connection between them is usually regarded as an established fact. The great majority of the recorded cases have occurred in insane persons, by whom this drug has been taken for a considerable period, and furthermore, the renewal of the sulphonal treatment after recovery has more than once been followed by a return of the symptoms. The allied drugs, trional and tetronal, appear, moreover, to be capable of producing a similar effect. ${ }^{2}$

Except in the slightest cases, the excretion of dark red urine is only one of a group of symptoms which appears to be connected with the administration of sulphonal. Of these vomiting, constipation (sometimes following an initial diarrhœa), and abdominal pain are the most constant. In a few cases febrile disturbance has been observed, but as a rule there is no rise of temperature. Paresis or paralysis of limbs, sometimes of an ascending type, with diminution of knee jerks, are not

\footnotetext{
1 Paper read before the Pathological Society of London, on November 5, 1895.

2 Vide Schultze, Deutsche med. Wchnschr., Leipzig, 1894, s. 152, and Herting, ibid., s. 343 .
} 
infrequently present, and ptosis and diaphragmatic paralysis have been met with.

In some instances, when the drug is stopped, the urine gradually resumes its normal colour, and recovery takes place, but in many cases the patients pass into a condition of collapse, with cyanosis, feeble and rapid pulse, and coldness of the extremities. They may sink into a condition of apathy, or may remain conscious up to the time of death, which quickly follows upon the development of these symptoms.

Very few post-mortem records are available, and the changes met with at the autopsies have not been conspicuous. Lesions of the brain have been noted, and in one case there was mitral stenosis. The liver has more than once shown advanced fatty degeneration.

In a case recorded by Percy Smith, ${ }^{1}$ there was much post-mortem staining and injection of the vessels of the stomach and intestines, and in the ileum there were one or two patches of submucous hæmorrhage; an observation which is of interest in connection with the views of Stockvis, which will be referred to later.

On the other hand, in a case reported by Oswald, ${ }^{2}$ the stomach and intestines showed nothing of special note, excepting some congestion of the first part of the duodenum, and in other parts corresponding to the coils.

In one of the cases recorded by Hammarsten ${ }^{3}$ also, although the unequal contraction of parts of the alimentary canal is carefully described, there is no mention of hæmorrhage or injection.

The kidneys have not shown any obvious naked-eye lesions, except such as could be referred to antecedent disease or senile change, but Stern and Oswald have described granular or necrotic changes in the epithelium of the glomeruli, and secreting portions of the tubules, and Kast ${ }^{4}$ observed hæmorrhage into the glomerular capsules in dogs poisoned with sulphonal.

That poisoning with sulphonal has some effect upon the kidneys is shown by the not infrequent appearance of albumen in the urine, when symptoms of poisoning develop, and by the presence of casts, hyaline, cellular or granular, more frequently than can be ascribed to accidentally associated renal disease.

We must not omit to mention that Franz Müller ${ }^{5}$ speaks highly of the therapeutic effect of alkalies, such as sodium bicarbonate, in these cases, and believes that such treatment, if adopted, as soon as the unfavourable symptoms develop, is capable of averting a fatal ending. Stockvis endorses this recommendation, and it is obvious that this method of treatment should in future be given a trial when the abovedescribed symptons are met with in patients taking sulphonal.

1 St. Thomas's Hosp. Rep., London, 1891, vol. xxi. p. 241.

${ }^{2}$ Glasgow Med. Journ., 1895, vol. xliii. p. 4.

${ }^{3}$ Upsala Läkaref. Förh., 1890-91, vol. xxvi. p. 267.

4 Arch.f. exper. Path. u. Pharmakal., Leipzig, 1892-93, bd. xxxi. p. 69.

5 Wien. klin. Wehnschr., 1894, s. 252.

30-JL. OF PATH. - VOL. III. 
Assuming then, as we are apparently justified in doing, that in the yreat majority of instances, the administration of sulphonal is the actual cause of the condition, we are nevertheless confronted with several important difficulties.

1. The action of the drug appears to be a cumulative one, and the patients have usually taken sulphonal for a considerable period of weeks or months before any ill effects are observed. Sometimes the symptoms have only appeared after the sulphonal has been discontinued, and in one of the cases recorded by Hammarsten an interval of no less than 9 days had elapsed since the last dose was taken.

2. Under ordinary circumstances the urine of patients taking sulphonal does not contain more hæmatoporphyrin than that of other healthy or diseased individuals, as was found by one of us on the examination of specimens kindly supplied from Bethlehem Hospital ${ }^{1}$ and of the large number of patients who take this drug only a very few exhibit the symptoms under discussion.

3. In a very large majority of cases the patients who do so suffer are females. We do not know of any recorded fatal case in a male, and, indeed, have only met with the mention of two cases of a slight character in such subjects. One of these, which is quoted by Franz Müller, ${ }^{2}$ was that of a man suffering from advanced tabes dorsalis, who had taken from half a gramme to a gramme of sulphonal nightly for 2 months; and the other, referred to by Percy Smith, was that of an old man, under the care of Dr. Savage, who had taken doses of 20 to 25 grs. nightly for more than a year.

In ordinary morbid cases, on the other hand, we do not find that sex has any influence upon the increase of the urinary hæmatoporphyrin.

4. Lastly, there are a few cases recorded by MacMunn, ${ }^{3}$ Ranking, and Pardington, ${ }^{4}$ Sobernheim, ${ }^{5}$ and others, in which dark red urine, rich in hæmatoporphyrin was passed by patients who had taken no sulphonal. In some of these, and notably those of Ranking and Pardington, in one of which acetanelide was given, general symptoms somewhat resembling those of the sulphonal patients were observed, but in others this was not the case. We do not propose at the present time to enter upon any discussion of the origin of urinary hæmatoporphyrin, but it is necessary to mention the views recently enunciated by Stockvis, ${ }^{6}$ who believes that the traces present in normal urines, and the larger amounts met with in disease, are alike derived from the blood pigment contained in the food; whereas he ascribes that present in cases of lead poisoning, and the far larger amounts met with in sulphonal urines, to hæmorrhage into the mucous membrane of

1 Journ. Path. and Bacteriol., Edin. and London, 1892, vol. i. p. 187.

2 F. Miiller, loc, cit.

3 Journ. Physiol., Cambridge, 1890, vol. xi.; Proc. Physiol. Soc., London, p. 13.

4 Lancet, London, 1890 , vol. ii. p. 607.

5 Deutsche med. Wehnschr., Leipzig, 1892, s. 566.

${ }^{6}$ Ztschr. f. klin. Med., Berlin, 1895, bd. xxviii. s. 1. 
the alimentary canal; the conversion of the blood pigment into hæmatoporphyrin being in these last cases materially aided by the presence of the sulphonal which causes the hæmorrhages. Concerning these views we would here merely state that our own observations and experiments make us hesitate to accept them as offering a complete explanation of the observed phenomena, and as regards normal and ordinary morbid urines, to question strongly the correctness of Stockvis's theory. The grounds for this attitude we hope to set out fully on a future occasion.

On the other hand, the observations to be described in this paper, add in one respect to the evidence, in opposition to the view that increase of urinary hæmatoporphyrin implies excessive blood destruction, for the presence in the urines, examined by us, of large quantities of this iron-free derivative of hæmoglobin was not attended by any corresponding increased excretion of iron. Blood examinations in the sulphonal cases are few in number. Percy Smith ${ }^{1}$ did not find in his cases any greater diminution of blood corpuscles, or of hæmoglobin, than is usually met with in cases of melancholia, from which disease the patients were suffering. In one case the number of red corpuscles per cubic mm. was no less than $4,600,000$.

In a case recorded by Oswald, ${ }^{2}$ three examinations of the blood, at intervals which are not stated, gave results varying between $3,520,000$ and $3,150,000$, a difference so small that no great significance can be attached to it. On the other hand, conspicuous anæmia is frequently mentioned in the clinical reports, and E. Schäffer ${ }^{3}$ describes a great diminution both of red corpuscles and of hæmoglobin in his case, but neither the hæmoglobinometer or hæmacytometer were employed.

Franz Müller ${ }^{4}$ states that in his case the percentage of hæmoglobin fell to 45 , and returned to 85 per cent., after the hæmatoporphyrinuria had ceased. He, however, gives no enumeration of the corpuscles.

Since the point to be ascertained is whether the passage of large amounts of hæmatoporphyrin in the urine is necessarily accompanied by excessive blood destruction, it is obvious that the force of even a few observations which do not reveal any successive hæmolysis, such as those of Percy Smith and Oswald, is not impaired by the fact that in other cases there is a condition of advanced anæmia. On the other hand, it should be noted that, as Salkowski has pointed out, a given quantity of hæmatoporphyrin represents more than twenty times its own mass of hæmoglobin, and this observer calculated that in one of his cases the daily excretion of hæmatoporphyrin corresponded to about $\frac{1}{32}$ of the total hæmoglobin of the patient.

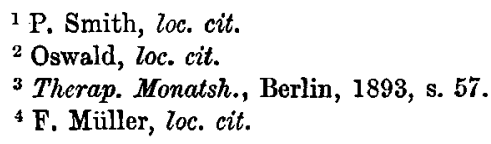


In all our specimens, as will be seen from the following account, very little urobilin was present, and in the third case, in which a special method was employed for its extraction, a quantity much smaller than that usually got from normal urine was obtained. Seeing that there is strong evidence that excess of urobilin in the urine accompanies excessive hæmolysis, the above fact is also significant in this connection.

The chemical and spectroscopic characters of the dark red urine of sulphonal poisoning have been carefully studied by Salkowski, Hammarsten, ${ }^{2}$ Stockvis, ${ }^{3}$ and MacMunn, ${ }^{4}$ and our object in bringing forward the following three cases which have come under our notice is to emphasise certain points to which these eminent observers have already called attention, and in certain particulars to supplement their results.

\section{Chinical Histonies.}

For the following Clinical Notes we are indebted to Drs. J. Delpratt Harris, W. M. Abbot Anderson, and M. J. Nolan, who respectively had charge of the cases, and from whom the specimens were received.

CASE 1 (from notes by J. Delpratt Harris).-Miss M. J. W., æt. 50, single ; chronic epileptic since 16 years of age. Suffered much from sleeplessness, and had taken sulphonal more or less continuously since May 1889. The drug has occasionally been omitted for a night or two, or even for a week, and then, insomnia supervening, patient has always returned to the sulphonal, and has oceasionally taken two doses of 20 grs. in 8 hours. It has always been found to agree well, and surpassed chloral in producing sleep; for a relatively larger amount of the latter was required to produce the effects of 20 grs. of sulphonal -her usual dose. Her sleeplessness, if neglected, resulted in attacks of epileptic mania, of which there were three in 7 years.

12th March 1895.- There is much pain in the lower part of the bowels over the region of the bladder, with tenderness over the right ovary and constant sickness. She was given a carminative mixture.

14 th March.-There is some constipation. Colocynth, calomel, and belladonna were given in pill. From this date to April 10 patient was: better. She was taking a tonic of gentian and nux vomica.

10th April.-Much abdominal pain again felt. It seemed to concentrate in the region of the bladder, and was increased by pressure in this region. Constant sickness and complete loss of appetite. Buchu and hyoscyamus in large doses had no effect on the pain.

13th April.-To-day it was noticed, after a fit, that the urine was of deep claret colour, but had no sediment. Temperature normal. Pulse quick and feeble. She is so weak that she cannot raise her hand from her bed. She suffers from piles, but there is little or no bleeding. Up to this date sulphonal had been taken almost every night, and on the 10 th she took 40 grs. during the night. The quantity of urine averaged 2 pints daily. There was never

\footnotetext{
1 Ztsehr. f. physiol. Chem., Strassburg, 1891, bd. xv. s. 286.

${ }^{2}$ Skandin. Arch. f. Physiol., Leipzig, 1892, bd. iii. p. 319.

3 Vederl. Tijdschr. v. Geneesk., Amsterdam, 1889, p. 413.

${ }^{4}$ See Percy Smith, loc. cit.
} 
any decided reaction with albumen tests. The colour was deepest about 13th April. It very gradually became less so, and by the 26th was but slightly coloured.

26th April.-Patient steadily became weaker and weaker, and very pale and anæmic, complaining of thirst, and looking like one very much exhausted from hæmorrhage. During the night she had an epileptic seizure, from which she never quite recovered, and died shortly afterwards. There was never any œdema of the extremities, or any ascites. No pulmonary symptoms until the very end, when cedema occurred. The pain and sickness were the first symptoms of any serious trouble (12th March). One month after this began the dark coloured urine was first passed, and a fortnight later death occurred. The abdominal pain was at first felt as high as the liver, later it was always over the bladder.

CASE 2 (from notes by W. M. Abbot Anderson).-Female, æt. 32 ; married at 20. Treated for hysteria, by Weir Mitehell method in 1892. Bad attack of erysipelas in 1887 . In 1893 showed evident signs of myxodema.

26th December 1894.-First showed signs of typhoid fever. This became of very severe type, and was followed by relapse. IIl 2 months, but well enough to go to Bournemouth at the end of February 1895. During this illness the patient slept badly, and took sulphonal in doses from 10 to $20 \mathrm{grs}$. The use of the drug continued from 26th December 1894 to early in May 1895. Towards the middle of April she returned to London from Bournemouth, and was progressing favourably. One day towards the end of April she unduly exerted herself, came home exhausted, and had to take to her bed. Shortly afterwards she passed dark red urine. From this time she continued to grow weaker and weaker, and died 11th May 1895 .

Case 3 (from notes by M. J. Nolan, County Down Asylum).Female, æt. 33, married ; millworker ; admitted to Downpatrick Asylum, 12th April 1895, suffering from acute melancholia of the agitated type. The attack commenced immediately after the birth of her child, 8 months previously. This child was nursed at the breast up to a few days before admission. Physical examination gave no evidence of organic disease. She had been partially refusing food for some weeks, and had been sleepless and constipated, and was in a very low state of health. The skin of the entire body was very darkcoloured, suggestive of the bronzing of Addison's disease, and the face, in addition, was of the peculiar cachexia seen in malignant disease; frequent and careful examinations, however, failed to determine any such conditions, nor did the patient complain of any symptoms associated with the diseases named.

She was put to bed, mild aperients and abundant nourishment were given, and 20 grs. of sulphonal were administered every second night to secure sleep. Sulphonal was continued in this way for a few weeks, by which time the condition had improved. The drug was now given only at irregular intervals (in doses of $20 \mathrm{grs}$.), whenever patient was reported as awake all the previous night. There was very little change in the mental and physical state from this time to the first week in July, when a violent relapse caused sulphonal to be given twice daily (10 grs. at 12 noon, and 20 grs. at 6 P.M.) for a fortnight; but as patient did not seem to derive the benefit expected the drug was abandoned on the 21 st July, and was not adninistered again.

A few days later she was quieter, and complained of weakness, which in. creased until the 31st July, when she was confined to bed. There was not at any time stupor, motor inco-ordination, pain, vomiting, feverishness, or gastro-intestinal irritation.

lst August.-Patient was very weak, complaining of general lumbar pain; temperature and pulse normal. For the first time the urine was noticed to be 
of a brownish tinge, but as it was mixed with a small quantity of fæees, it was difficult to determine the true character of the pigmentation. The quantity passed was not over the average.

2nd August.-The discoloration was more pronounced, the urine being now of the shade of old port wine. Held up against the light it was quite tawny, showing no cloudiness or "smoky" appearance. On examination, albumen and sugar were found absent, and for the first time hæmatoporphyrir was suspected. Thus the condition began 10 clear days after sulphonal had been wholly abandoned. It continued and increased daily to the date of death, 9th of August, which was 9 days from the date of its first appearance. The elinical symptoms during these 9 days were confined to intense weakness (the pulse being very small and slow), and a change in the colour of the skin. The dark tinge of the latter became clearer, owing to the increased anæmia, which was indicated by a pearly white sclerotic, blanched lips and fauces. The temperature became slightly subnormal, and respiration feeble. There was no indication of nephritis, which was daily looked for. After death the skin was of a whity-brown hue. No post-mortem was allowed.

It will be observed that all three patients were females, all had taken sulphonal, and in all the cases death followed shortly after the development of the symptoms, the intervals being 13,14, and 9 days respectively.

In Case 1 the symptoms conformed to the ordinary type. A point of special interest in this case was the long period during which sulphonal had been taken without any ill effect (no less than 4 years). The pain in the region of the bladder here complained of has been met with in other cases, and was a conspicuous feature in the cases described by Ranking and Pardington, in which sulphonal was not given. The second and third cases were peculiar in the absence of gastrointestinal symptoms.

In Case 3, as in one of Hammarsten's cases, above referred to, an interval of no less than 10 days elapsed between the administration of the last dose of sulphonal and the onset of the symptoms. In connection with the pigmentation of the skin in Case 3, which was present before any sulphonal was taken, it is interesting to note that caseation of the suprarenals and bronzing were present in a sulphonal case, referred to by Oswald as having occurred in the Edinburgh Royal Infirmary. We much regret that we have no postmortem observations to add to the few already published.

\section{General Character of the Urine.}

In all 3 cases the specimens came into our hands for examination only a few days before the death of the patient. Any attempt to make a series of observations, either on the pigmentation or general condition of the urine, was therefore prevented. The specimens examined were passed when the condition of dark urine was at its height. Their colour was that of port wine. All the specimens were acid, and of low specific gravity (1010-1013). The percentage of urea 
was about the same in each ( 2 per cent). In none was more than a minute trace of albumen present; one specimen from Case 1 was in fact entirely free; Case 3 showed more than the others, but the quantity was extremely small. In spite of this, the deposits obtained by use of the centrifuge contained abundant tube casts. In the absence of any renal symptoms, and in the practical absence of albuminuria, this fact seemed somewhat surprising; but the literature of the subject as stated above shows that the presence of casts is common in these cases. In ours they were very numerous, indeed. In addition to the ordinary hyaline and epithelial varieties, there were many wellformed, finely granular casts, of purplish colour, which appeared to be almost wholly made up of pigment. The cells composing the epithelial casts were deeply pigmented, and the deposit comprised numerous isolated epithelial cells, and many large granular leucocytes, all of which contained much pigment. This description is true of all three cases.

\section{ABSENCE OF IRON FROM THE URINE.}

It seemed a point of some interest to determine whether the great increase in the excretion of the iron-free derivative of hæmoglobin was accompanied by any increased excretion of iron, present in some other combination. In Case 1, 8 oz. of urine were evaporated to dryness, great care being taken to prevent contamination with extraneous iron. The residue was burnt in a muffle-furnace, the ash dissolved in hydrogen chloride, and, after the addition of a little hydric nitrate, the solution was evaporated to dryness. Taken up again in a little dilute hydrogen-chloride and filtered, the solution was made just alkaline with ammonia, and boiled. The ammonia precipitate was filtered off, dissolved in 2 c.c. of dilute hydrogen chloride, the solution divided into two parts, and tested $(a)$ with sulphocyanide, and (b) with ferrocyanide of potassium. Neither reagent gave the least trace of colour. Eight oz. is perhaps a somewhat small quantity to use for this purpose, but control specimens of normal urine gave in several cases distinct iron reactions from the same quantity, so there can be no doubt that any increase in the urinary iron was absent from Case 1. The other cases (in which, however, still smaller quantities had to be used) also gave negative results.

\section{SPECTROSCOPIC ExamiNation OF THE URINE.}

CASE 1-Specimen A.-The urine had a deep port-wine colour. In a layer of $1.5 \mathrm{~cm}$. a band was seen in the red from $\lambda 624$ to $\lambda 612$. This is the first band of alkaline hæmatoporphyrin - from the $D$ line onwards the spectrum was completely obscured. 
Diluted with an equal quantity of water in a depth of $1.5 \mathrm{~cm}$. the following bands were seen :-

1. $\lambda$ 624-612
2. $\lambda 589-573$ rather faint.
3. $\lambda$ 546-532.

From D onwards towards the blue the spectrum was much obscured. Absolute darkness extended from a band $\lambda 515$. read:-

On the addition of a few drops of hydrogen chloride the bands

1. $\lambda 597-589$.

2. $\left\{\begin{array}{c}\lambda \text { 576-570. } \\ \text { shading. } \\ \lambda \text { 558-540. }\end{array}\right.$

These are the bands of acid hæmatoporphyrin. There was darkness from $\lambda 529$.

On shaking with acetic ether a pink ethereal extract was obtained, which showed the following bands:-

Shading to $\lambda 642$.

1. $\lambda$ 628-620.

2. $\lambda 601-597$.

3. $\lambda$ 586-569.

4. $\lambda$ 540-525.

5. $\lambda \cdot 511-482$.

This is a slightly modified neutral hæmatoporphyrin spectrum.

The subjacent liquid, after treatment with the acetic ether, was of deep brown colour, showing complete absorption of the spectrum from $\lambda 549$.

On the addition of a drop of hydrogen chloride the pigment left the acetic ether for water, forming a deep pink solution, which showed the acid hæmatoporphyrin bands with great intensity. No urobilin band. Readings-

\section{$\lambda 597-\lambda 589$. \\ $\lambda 576-\lambda 560-543$.}

A more concentrated specimen, similarly treated, showed a faint urobilin band.

The soda method and the ammonium chloride method were quite unable to cope with the amount of hæmatoporphyrin here present, the precipitates being able to carry down only a small portion.

The extract from the soda precipitate was peculiar in that the hæmatoporphyrin could not be, by any means, persuaded to go into chloroform.

Specimen B.-This was much darker than the earlier specimen just described. The colour was almost black. Shaken with acetic ether, it yielded an extract less distinctly pink than that obtained by the same method from Specimen A (v. supra). After extraction with 
the acetic ether the urine retained a deep brown colour, and absorbed the spectrum quite up to the red.

About $4 \mathrm{oz}$. were treated by Salkowski's barium method. The precipitate had a deep mauve colour, the filtrate was yellow. The precipitate was washed and treated with alcohol acidified with hydrogen sulphate.

The extract had a very deep colour. From the acid liquid, after the addition of water, chloroform took a very deep red colour. The supernatant liquid was poured off and water substituted. On shaking, a mahogany-brown pigment left the chloroform, and also a little hæmatoporphyrin. After reperted washing, the chloroform was pink, and showed the five-banded spectrum of neutral hæmatoporphyrin with great intensity.

A specimen of the original urine was repentedly extracted with acetic ether.

The first and second ethereal extracts were red-pink, and showed the following bands:-

1. $\lambda$ 628-624, fainter.

$\left.\begin{array}{l}\text { 2. } \lambda \text { 586-570 } \\ \text { 3. } \lambda \text { 549-526 }\end{array}\right\}$ very dark.

4. $\lambda$ 508-486, faint.

The appearances suggested that much two-banded (oxy-hæmoglobinlike) hrmatoporphyrin was mixed with a small quantity of the ordinary kind.

The third ethereal extract was reddish-brown, and showed the two dark bands very clearly. No band was seen in red, and that in blue was very faint.

Case 2.-The urine had a dark port-wine colour. Filtered, and examined direct in a layer of $2.25 \mathrm{~cm}$., the specimen allowed only a little red to penetrate. With a wider slit a band was seen-

On dilution-

$\lambda$ 624-612, darkness from $D$.

1. $\lambda 624-\lambda 612$, faint.

2. $\lambda 586-\lambda 573$.

3. $\lambda 549-\lambda 529$.

General darkness from $\lambda 515$.

On adding lyydrogen chloride the acid hæmatoporphyrin lands appeared-

1. $\lambda$ 597-589.

2. $\lambda$ 560-543.

On shaking with amylic alcohol, a very intense spectrum of alkaline hrematoporphyrin was obtained-

1. $\lambda 626-618$.

2. $\lambda$ 597-586-56 .

3. $\lambda$ 549-532.

4. $\lambda 51 \tilde{\nu}-$ ?

The extract was red, the subjacent fluid dark brown. 
Salkowski's barium method gave a red precipitate, the filtrate being pale yellow.

The precipitate was washed and treated with alcohol, acidified with hydric chloride.

The acid extract had a deep red colour (not pink), and showed the acid bands well, and with ammonia the alkaline bands strongly, but the pigment could not be got to go into chloroform.

The Salkowski extract was neutralised with ammonia, and evaporated nearly to dryness. On adding a drop of hydrogen chloride and shaking with acetic ether, the ether became pink, and showed a three-banded spectrum, as follows:-

$$
\begin{aligned}
& \text { 1. } \lambda \text { 570-536. } \\
& \text { 2. } \lambda \text { 532-517. } \\
& \text { 3. } \lambda \text { 506-481. }
\end{aligned}
$$

A specimen of the same urine shaken with acetic ether gave a reddish-pink extract, which showed the five-banded neutral spectrum :-
1. $\lambda$ 628-620.
2. $\lambda 601-592$.
3. $\lambda$ 586-567.
4. $\lambda$ 549-526.
5. $\lambda$ 513-484.

CASE 3.-The colour of the specimen resembled that of dark port-wine.

A portion was repeatedly extracted with acetic ether. The extracts were red, and showed the bands of alkaline hæmatoporphyrin with decreasing intensity in each successive extract.

After three extractions the urine no longer showed these bands, but still had a dark red colour. This specimen, from which almost all the hæmatoporphyrin had beel extracted, when treated with bariumchloride and hydrate (Salkowski's process) gave a purple precipitate, which, when treated with alcohol, acidified with sulphuric acid, gave a reddish-brown extract, which showed the bands of acid hæmatoporphyrin very faintly, and much general absorption from the green onwards. On the addition of ammonia the liquid became brown, and no distinct bands were seen.

The original urine, diluted with water, showed a band in red ( $\lambda$ 6200-6100), a shading from $\lambda$ 6010-5825, and complete absorption beyond. In a thinner layer, the following spectrum was seen :-

$$
\begin{aligned}
& \text { 1. } \lambda 6200-6100 \text {, faint. } \\
& \text { 2. } \lambda \text { 5860-5570, faint. } \\
& \text { 3. } \lambda \text { 5430-5320, very dark. } \\
& \text { 4. } \lambda \text { 5080-4690, very dark. }
\end{aligned}
$$

These are the bands of alkaline hæmatoporphyrin, but the great relative intensity of the third and fourth bands, and a shading 
connecting them, showed the presence of a second pigment. On the addition of sulphuric acid, the bands of acid hrematoporphyrin appeared, and also a very broad band with ill-defined edges from about $\lambda$ 5290-4690.

To another portion more than its own bulk of rectified spirit was added, which caused turbidity, and, on filtering, a brown precipitate was collected. This yielded hrematoporphyrin to alcohol, acidified with acetic acid, showing that in this, as in Stockvis's case, some of the hæmatoporphyrin was insoluble in neutral alcohol.

The residue upon the filter was readily dissolved by a dilute solution of caustic soda in water, yielding a brown solution which showed the following bands:-
1. $\lambda 6200-6100$, faint.
2. $\lambda$ 5760-5570, faint.
3. $\lambda$ 5460-5370, dark.
4. $\lambda$ 5170-4910, dark.
5. $\lambda$ 4720-4570, faint.

Here the third and fourth bands were far darker than the others, which agree with those of alkaline hamatoporphyrin, the fifth band in the extreme violet being one which is only seen when an excess of alkali is present. This band disappeared on the addition of acetic acid.

The dark third and fourth bands were those which were so conspicuous in the original urine, and the spectrum was obviously either a modification of that of alkaline hæmatoporphyrin, or that of a mixture of two pigments, one of which was ordinary hæmatoporphyrin. That the latter was not the case was shown by the fact that on the addition of sulphuric acid the bathds of acid hæmatoporphyrin did not appear, but only an ill-defined absorption band from $\lambda$ 5290- $\lambda 4770$.

Another portion of the original urine treated by Salkowski's method yielded a brown precipitate, from which a deep red alcoholic extract was obtained, which showed the bands of acid hæmatoporphyrin with great intensity, but there was also much general absorption from the green onwards. On the addition of ammonia, the liquid became much paler, brown in colour, and showed the bands of alkaline hæmatoporphyrin. Only a trace of urobilin was present in this urine.

It should be mentioned that in this case the examination of the urine was not made until some weeks after it had been passed, and there was reason to believe that when fresh it contained little, if any, ordinary hæmatoporphyrin. Such development of the pigment in the urine, on standing, has been noticed by several observers.

In all the above specimens there was evidence of the presence of a reddish-brown pigment, producing a great general absorption of the more refrangible portion of the spectrum, but showing no bands. 
Owing to this, the urine always remained deeply coloured after all or nearly all the hematoporphyrin had been extracted.

In reviewing the results of the above examinations, one point to which we desire to call attention is that the methods which we have found most serviceable for the detection of hematoporphyrin in ordinary morbid urines (viz. that by the addition of caustic soda, and extraction of the pigment from the washed phosphate precipitate, and that by saturation of the urine with ammonium chloride, and treatment of the urate precipitate with a mineral acid) are useless when we are dealing with such large quantities of the pigment as were present in the urines above described. Both the methods referred to - the former especially - are extremely delicate, and serve for the detection of the traces present in normal urines, but they are not true precipitation methods, the pigment being merely carried down upon the precipitates of phosphates and urates respectively, to which, however, it clings with sufficient tenacity to allow of the washing of the sediments.

Either of these methods, when applied to the sulphonal urines, leads to the separation of only a very small part of the contained hamatoporphyrin, which is here present in quantities which completely overtax the carrying power of the precipitates.

Salkowski's method of precipitation with barium chloride and hydrate removes all the abnormal pigments, leaving the filtrate of a pale yellow colour, but, as we have seen, much of the pigment so carried down is, in most instances, not hæmatoporphyriu.

We have found the method above described, of repeated extraction with acetic ether, very useful for the separation from each other of the abnormal pigments, and the earlier extracts so obtained contain much less of the pigments other than hrematoporphyrin than do similar extracts obtained by shaking the urine with amylic alcohol.

Another point upon which, in our opinion, sufficient stress has not hitherto been laid, is this, viz. that the deep colour of these sulphonalurines is only in part due to the hamatoporphyrin which they contain.

A specimen of urine may show, when examined with the spectroscope in a sufficiently deep layer, the entire spectrum of the so-called alkaline hæmatoporphyrin so distinctly that the bands can be accurately measured, and yet have merely a rich orange colour; nor have we been able, by adding to normal urine isolated urinary hæmatoporphyrin in such quantities that the absorption bands were seen with great intensity, to reproduce at all the colour of the sulphonal specimens.

On the other hand, in the sulphonal urines, the bands of hæmatoporphyrin-although, as far as the general absorption allowed them to be seen, they were quite distinct-did not in any way 
correspond in definition to what might have been expected, if the tint of the liquid had been largely due to that pigment. In some specimens the quantity present was much larger than in others, but those which contained most hæmatoporphyrin were not the darkest in colour.

In some instances there was reason to believe that much of the additional abnormal colouring matter was in the form of derivatives of hæmatoporphyrin, but even this cannot be asserted of all the cases.

In Case 1 there was present, in addition to much ordinary hæmatoporphyrin, a large quantity of a pigment, undoubtedly allied to it, which showed two absorption bands resembling those of hæmoglobin, and in this the specimens agreed with that examined and described by Stockvis, who separated the two-banded pigment from the ordinary hæmatoporphyrin by dialysis. The two-banded pigment under discussion resembled that found by one of us in urate sediments from urines fairly rich in hæmatoporphyrin, and a similar spectrum is yielded by the zine compound of that pigment.

In all three cases the colour of the urine appeared to be in great part due to a reddish-brown pigment, which showed no bands, but largely absorbed the violet end of the spectrum. It seems highly probable that this was identical with the reddish-brown pigment found by Harnmarsten in three out of the four specimens which he examined, and to which he also attributed an important share in their coloration. This is a point of some importance, since there is a tendency to ascribe to any band-yielding pigment or pigments which they may contain an undue share in the coloration of specimens of urine. We see this well exemplified in the ascription of the colour of normal urine to urobilin, a pigment which, in solutions so dilute as to show a band such as yielded by normal urines, when, indeed, they yield a band at all, has hardly any appreciable tint. We are also prepared to maintain that the dark colour of the urine in cases of pernicious anæmia is only in small part due to the excess of, urobilin which it is wont to contain.

In Case 3, as in Stockvis's case, a considerable quantity of the abnormal pigment was precipitated by the addition of an excess of alcohol, and the precipitate so formed consisted in part of hæmatoporphyrin which was taken up by alcohol acidified with acetic acid, and in part of a brown pigment, readily soluble in alkalies, and which showed a spectrum somewhat resembling that of alkaline hæmatoporphyrin, but which, on the addition of a mineral acid, yielded only a broad and very ill-defined absorption of the blue and green.

It is found that samples of hæmatoporphyrin, derived from different urines are apt to exhibit curious differences both from each other and from specimens prepared from hæmoglobin. Such slight differences as relate merely to displacements of the absorption bands can be explained as the results of differences of solvent, of 
the degrees of acidity or alkalinity of the solutions, and such-like causes, but, as we have seen, there are also observed remarkable differences of solubility, examples of which have been quoted above, and are perhaps more conspicuous in dealing with the pigments from these dark red urines than with those from ordinary morbid specimens.

We may quote the precipitation by alcohol, in which liquid hrematoporphyrin is usually freely soluble, and the fact that the hæmatoporphyrin present in Cases 1 and 2, unlike any other specimens that we have ever met with, refused entirely to go into chloroform out of an aqueous-alcoholic solution acidified with acetic acid.

Such differences have been observed by all who have made a special study of such urines, and we have yet to learn how far they are due to actual differences in the pigments themselves, and how far to the disturbing influence of impurities present in the solutions dealt with. 